\title{
Assessment of functional outcome of surgical management of proximal humerus fracture treated with PHILOS plate
}

\author{
Jairam D. Jagiasi, Mihir R. Patel*, Sagar G. Daliya, Amol Bochare, Manan Vora
}

Department of Orthopedics, Dr. R. N. Cooper Hospital and HBT Medical College, Mumbai, Maharashtra, India

Received: 20 May 2018

Revised: 08 July 2018

Accepted: 09 July 2018

\author{
*Correspondence: \\ Dr. Mihir R. Patel, \\ E-mail: mrpatel1981@gmail.com
}

Copyright: (c) the author(s), publisher and licensee Medip Academy. This is an open-access article distributed under the terms of the Creative Commons Attribution Non-Commercial License, which permits unrestricted non-commercial use, distribution, and reproduction in any medium, provided the original work is properly cited.

\begin{abstract}
Background: Proximal humeral fractures were treated conservatively in the past and often had compromised functional results. With the advancement of surgical techniques, these fractures, especially displaced, are now more often managed operatively; to meet the needs of the patient, provide early rehabilitation and better functional outcome. The aim of this study was to assess the functional outcome of operative management of proximal humeral fractures with Philos plate fixation.

Methods: In this prospective study, 30 patients aged 19-75 years (mean age 47.1 years) with fractures of the proximal humerus, including two-, three-, and four-part fractures, were treated by open reduction internal fixation with Philos plating. Patients' functional outcomes were evaluated based on subjective (35 points) and objective (65 points) parameters, as per the constant scoring system.

Results: Functional outcome based on the constant scoring system of the patient at 6 month follow-up were compared. Excellent results were seen in 12 patients (40\%), 2 had very good results $(6.66 \%), 9$ patients were having good $(30 \%)$ and 6 had fair (20\%) functional outcome. One patient had poor functional results (3.33\%). Avascular necrosis (AVN) of the humeral head was observed in one patients.

Conclusions: Philos plate fixation for proximal humeral fractures provides good stable fixation with good functional outcome and is a feasible option.
\end{abstract}

Keywords: Philos plating, Proximal humerus fractures, Shoulder fractures

\section{INTRODUCTION}

Proximal humeral fractures are the second most common upper-extremity fracture and the third most common fracture,most common being hip fracture and second most being distal end radius, in patients who are older than sixty-five years of age. They account for about $5 \%$ of all injuries to appendicular skeleton. ${ }^{1}$ In young individuals, high velocity trauma is the cause of these fractures, whereas simple fall can be the cause in older individuals because of osteoporosis. The majority of these fractures are stable, nondisplaced or minimally displaced and can be treated nonoperatively. ${ }^{2}$
Approximately $20 \%$ of displaced proximal humeral fractures may benefit from operative treatment. ${ }^{3}$ Many techniques of surgical management have been described, but no single approach is considered to be the standard of care. $^{4}$

Many techniques have evolved over time to treat displaced or comminuted proximal humerus fractures. Percutaneous pinning and intramedullary nailing have been employed with generally satisfactory results and carry a low risk for infection, soft tissue disruption, and blood loss. ${ }^{6}$ However, many of these constructs are less 
stable than open reduction and internal fixation (ORIF) with locking plates. ${ }^{5,6}$

Open reduction and internal fixation (ORIF) with locking plating is proving to be a promising option in the treatment of displaced, comminuted proximal humerus fractures. This approach offers several potential advantages compared with more traditional open techniques. ${ }^{8}$ These benefits include improved fracture stability because of the fixed-angle construct, particularly in more comminuted fracture patterns and in osteoporotic bone; a short period of immobilization with the opportunity for earlier rehabilitation. ${ }^{9}$ This study is conducted to evaluate the results in terms of functional outcome of proximal humeral fractures treated by anatomic locking compression (PHILOS- proximal humerus interlocking system) plate.

\section{METHODS}

This prospective interventional study was conducted at Dr. R. N. Cooper Hospital and HBT Medical College, Mumbai from May 2016 to April 2018, over a span of 2 years. Functional outcome in the form of constant score were recorded at 6 months follow up and were compared.

\section{Inclusion criteria}

Inclusion criteria were patients of age above $18 \mathrm{yrs}$; two part, three part and four part fracture of proximal humerus.

\section{Exclusion criteria}

Exclusion criteria were children and adolescent patients less than 18 yrs (non fusion of epiphysis); pathological fractures / old fractures; patients with compound fractures; patient with other fractures.

\section{Evaluation of patients}

- Careful history of injury was elicited (from the patients and/or attendants) and the severity of trauma was assessed on admission.

- The general conditions of the patient were assessed and any signs of associated injuries were sort for and evaluated.

- The patients were clinically assessed to evaluate the local injury. The local examination was done for swelling, deformity, loss of function and altered attitude. Any nerve injury was also looked for and noted. Axillary nerve assessed by looking for anaesthetic patch over lateral aspect of shoulder.

- Radiograph; antero-posterior view and axillary view of proximal humerus were taken and classified as per Neer's classification.

- The patient was taken for surgery after routine investigation and after obtaining anesthesia fitness. The consent for surgery was also taken from the patient and attendants after explaining the procedure and possible complications.

\section{Operative technique}

- The standard deltopectoral approach was used in all cases with patient in beach chair position.

- After freshening the fracture fragment, fractures were reduced. Temporary fixation with K- wires was performed to hold the fracture reduction.

- The plate was positioned distal to the tip of the greater tuberosity.

- The distal humeral screws were having bicortical purchase. Proximal locking screws were extended till subchondral area.

- An image intensifier was used to check the quality of the reduction, stability of the construct, plate position, and length as well as position of the screws to avoid penetration of the locking screws into the glenohumeral joint in all the cases.

- After adequate fixation was confirmed, the wound was closed in layers with proper wound dressing

\section{Postoperative management}

- All patient's operated limb were supported using arm pouch with cuff and collar sling.

- Appropriate antibiotics and analgesics were used.

- Immediate post operative radiographs were taken to determine the bone alignment and maintenance of reduction.

- $\quad$ Passive range of motion and pendulum exercises are begun immediately postoperatively

\section{Follow up}

- All patents were followed at 2 weeks and 4 weeks. Further follow ups were at 8 weeks, 3 months and 6 months.

- The active ranges of motion were started at 1-2 weeks. Postoperatively, depending on stability of osteosynthesis and bone quality.

- The sling is discontinued by 8-12 weeks depending upon fracture stability.

- The patients were examined clinically and radiologically. Assessed for range of motion and bony union and complication.

\section{Functional outcome evaluation}

The final results were evaluated using Constant-Murley score. This system base on 100 point score composed of a number of individual parameters. The subjective parameters assess the degree of pain the patient experiences and the ability to perform normal tasks of daily living as they apply to him or her in both activity and position related terms. Both of these assessments are subjective and are carried out independently prior to objective testing of active motion range and shoulder 
power. Constant score were categorized as $<30$ =unsatisfactory; 30-39=fair; 40-59=good; 60-69=very good; and 70 and over $=$ excellent. $^{20}$

\section{Statistical tool}

Simple statistical tools of mean and percentage were use, as this study is not a comparative study.

\section{RESULTS}

The total numbers of cases in our study were 30. Age range was from 19 to 75 years, with mean age of 47.1 years. Patients with age of more than $>50$ were 13 (43.33\%) and those between 40-50 were 7 (23.33\%) and less than 40 were $10(33.33 \%)$ (Figure 1).

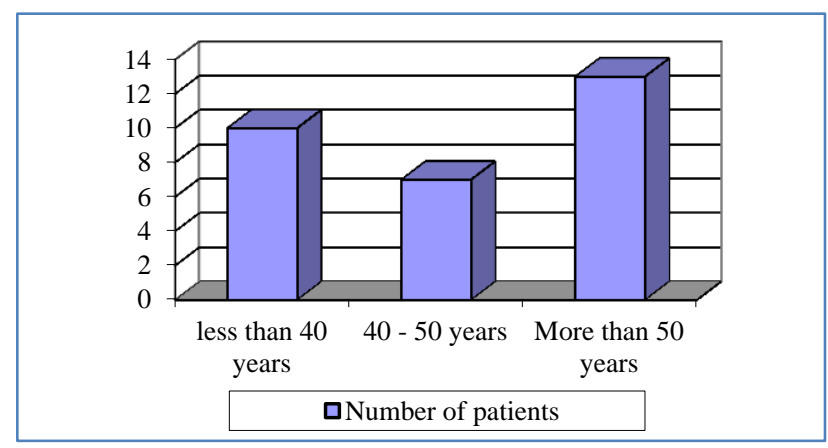

Figure 1: Patients in different age groups.

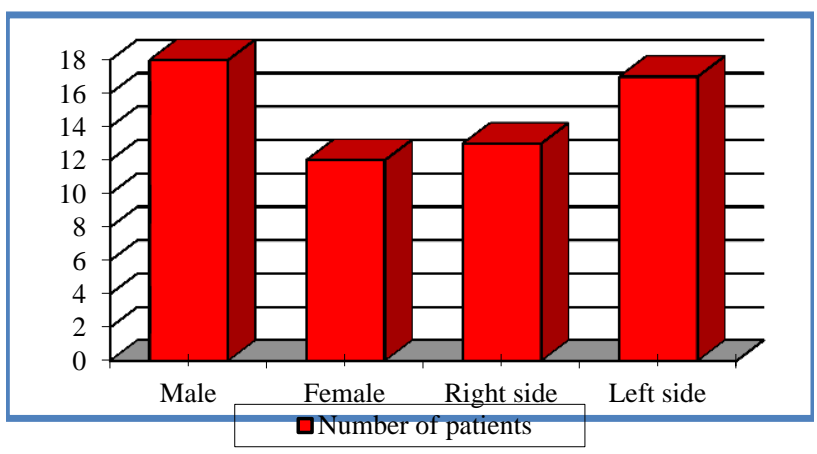

Figure 2: Patient distribution as per sex and side of fracture.

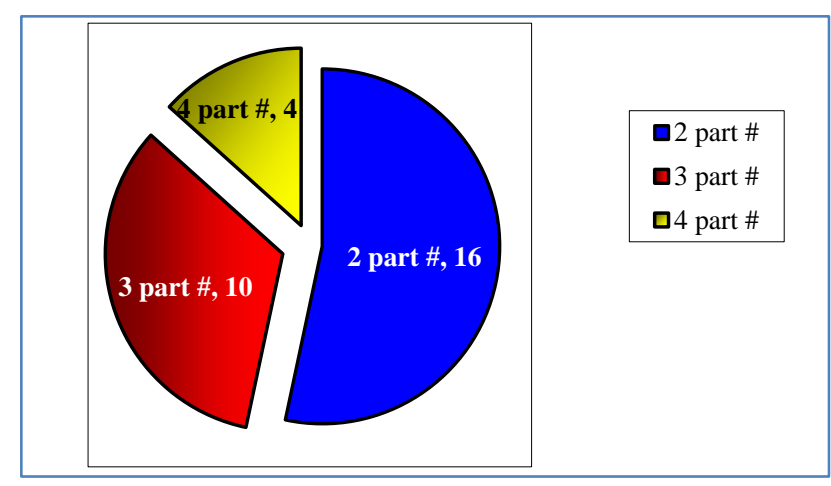

Figure 3: Distribution as per type of fracture.
The sex wise distribution, 12 were females $(40 \%)$ while 18 were males $(60 \%)$ with $\mathrm{m}$ : $\mathrm{f}$ sex ratio of $3: 2.17$ patients had fracture of left side $(56.66 \%)$ and 13 had right side fracture(43.33\%) (Figure 2).

Out of total cases, 12 cases were due to road traffic accidents (RTA) / high trauma force (40\%) compared to trivial/domestic fall which was reason in 18 of the cases $(60 \%)$. As per Neer's type; 16 were 2 part $(53.33 \%), 10$ were 3 part $(33.33 \%)$ while 4 were 4 part $(13.33 \%)$ fractures (Figure 3).

Table 1: Patient outcome as per constant score.

\begin{tabular}{|lll|}
\hline $\begin{array}{l}\text { Grading of constant } \\
\text { score }\end{array}$ & $\begin{array}{l}\text { Number of } \\
\text { patients }\end{array}$ & $\begin{array}{l}\text { Percentage } \\
(\%)\end{array}$ \\
\hline Excellent $(\mathbf{7 0})$ & 12 & 40 \\
\hline Very Good $(\mathbf{6 0 - 6 9})$ & 2 & 6.66 \\
\hline Good (40-59) & 9 & 30 \\
\hline Fair $(\mathbf{3 0 - 3 9 )}$ & 6 & 20 \\
\hline Poor $(<\mathbf{3 0})$ & 1 & 3.33 \\
\hline
\end{tabular}

As per grading of the constant score to categorize the outcome of patients, in present study, 12-excellent (40\%), 2-very good (6.66\%), 9 -good (30\%), 6- fair (20\%) and 1 - poor $(3.33 \%)$ (Table 1$)$.

Total mean constant score was 61.8. The mean constant score in cases above 45 yrs of age is 50.53 and the mean constant score in patients below $45 \mathrm{yr}$ of age is 72.91. No intra-operative complication was seen in any of the cases. One case of impingement was seen for which implant removal was done and the score improved after the implant removal. 1 case of AVN was seen which was then operated with shoulder hemiarthroplasty.

\section{DISCUSSION}

The proximal humeral fractures operative treatment of is a challenge for orthopaedic surgeons and has been controversial. Most of the un-displaced proximal humerus fracture can be treated conservatively. For displaced proximal humerus fractures, treatment with conventional plates and screws have been reported with high rates of unsatisfactory outcomes and complications. ${ }^{10}$ Locking plates are angular stable plates which has advantage of secure fixation in metaphyseal and osteoporotic bones. Locking plates are proven with biomechanical studies that they resist physiological loads more effectively. ${ }^{11,12}$ There are many clinical studies which indicate that proximal humerus locking plates have good result in proximal humerus fractures. ${ }^{13-15}$

The average age incidence in present series of 30 patients analyzed, was 47.1 years, which was consistent with the age incidence in studies done by Egol et al, (61 years) and the average age incidence in Gerber et al, study was 44.9 years. $^{18,19}$ Further as compared with other studies, present study showed a higher incidence of fractures in men than in women. The gender ration was 3:2. This 
higher ration can be explained by a higher involvement of male in day to day activities in compare to female.

In our present study, fracture occurred on right side in 13 patients and on left side in 17 patients. Gerber reported, in their series of 34 fractures, 16 were on left side and 18 were on right side. ${ }^{19}$ Two-part fracture was observed to be the most common fracture pattern in the present study. Similar observations had also been reported by Björkenheim et al. ${ }^{8}$ By contrast, Koukakis et al, Rose et al, Siwach et al, and Fankhauser et al had reported a significant higher incidence of three-part fractures in their series. $^{13,14,21,22}$

Thyagarajan et al in their study on 30 patients reported an average Constant score of 57.5 , with mean age of 58 years (range 19-92 years) and fractures were Neer's 2part, 3-part, and 4-part fractures. ${ }^{16}$ Aggarwal et al found moderate to excellent outcome in $90 \%$ of patients in their study. Constant score for younger patients was also significantly higher $(\mathrm{p}=0.12)$. The mean age of the patients was reported as 58.51 years (range 23-81 years) and fracture types were Neer 2-part, 3-part, and 4-part fractures and fracture dislocations. ${ }^{17}$ In our study mean constant score was 61.8 which is comparable with other studies mentioned.

AVN of the humeral head is a known complication of proximal humeral fracture, reported most commonly with four-part fractures. Kilic et al used Philos for fixation of proximal humeral fractures and reported AVN in only one of 22 patients in their series. ${ }^{23}$ Korkmaz et al did not observe osteonecrosis in any of their 41 patients operated using the same implant. ${ }^{24}$ Frangen et al reported osteonecrosis in 11 patients (6 were partial and 5 total). ${ }^{7}$ In our study, there was avascular necrosis (AVN) of the humeral head in only one patient.

\section{CONCLUSION}

This study was done to evaluate the functional outcome following surgical management of proximal humerus fracture by PHILOS plate. Adequate surgical skills and surgeon's experiences with the surgical technique are necessary to achieve correct implant fixation and avoid intraoperative errors. Also postoperative physiotherapy plays an important role in rehabilitation of the patient to provide good results. In conclusion, the internal fixation of proximal humeral fractures with the use of PHILOS plates yields reliable results when utilized correctly. With the use of correct surgical technique by a competent surgeon, the anatomic locking compression plate is a suitable option for surgical management of proximal humeral fractures providing a good functional outcome.

Funding: No funding sources Conflict of interest: None declared

Ethical approval: The study was approved by the institutional ethics committee

\section{REFERENCES}

1. Court Brown CM, Caesar B. Epidemiology of adult fractures: A review Injury. 2006;37:691-7.

2. Young TB, Wallace WA. Conservative treatment of fractures and fracture-dislocations of the upper end of the humerus J. J Bone Joint Surg Br. 1985;67(3):373-7.

3. Rose SH, Melton LJ 3rd, Morrey BF, Ilstrup DM, Riggs BL. Epidemiological features of humeral fractures Clin Orthop. 1982:168:24-30.

4. Sahu RL. Philos Locking plates in proximal humerus fractures literature review. Internet $\mathbf{J}$ Health. 2010;11:1.

5. Aaron D, Shatsky J, Paredes JC. Proximal humeral fractures: internal fixation. J Bone Joint Surg Am. 2012;94(24):2280-8.

6. Murray IR, Amin AK, White TO, Robinson CM. Proximal humeral fractures: current concepts in classification, treatment and outcomes. J Bone Joint Surg Br. 2011;93(1):1-11.

7. Frangen TM, Müller EJ, Dudda M, Arens S, Muhr G, K€alicke T. Proximal humeral fractures in geriatric patients. Is the angle-stable plate osteosynthesis really a breakthrough? Acta Orthop Belg. 2007;73:571-9.

8. Björkenheim JM, Pajarinen J, Savolainen V. Internal fixation of proximal humeral fractures with locking compression plate: A retrospective evaluation of 72 patients followed for a minimum of 1 year. Acta Orthop Scand. 2004;75:741-5.

9. Flores S, Merk BR. Two-part surgical neck fractures of the proximal part of the humerus: A biomechanical evaluation of two fixation techniques. J Bone Joint Surg Am. 2006;88:225864.

10. Kristiansen B, Christensen SW. Plate fixation of proximal humeral fractures. Acta Orthop Scand. 1986;57:320-3.

11. Lever JP, Aksenov SA, Zdero R, Ahn H, McKee MD, Schemitsch EH. Biomechanical analysis of plate osteosynthesis systems for proximal humerus fractures. J Orthop Trauma. 2008;22:23 9.

12. Seide K, Triebe J, Faschingbauer M, Schulz AP, Püschel K, Mehrtens G, et al. Locked vs. unlocked plate osteosynthesis of the proximal humerus A biomechanical study. Clin Biomech (Bristol, Avon) 2007;22:176-82.

13. Koukakis A, Apostolou CD, Taneja T, Korres DS, Amini A. Fixation of proximal humerus fractures using the PHILOS plate: Early experience. Clin Orthop Relat Res. 2006;442:115-20.

14. Fankhauser F, Boldin C, Schippinger G, Haunschmid C, Szyszkowitz R. A new locking plate for unstable fractures of the proximal humerus. Clin Orthop Relat Res. 2005;430:176-81.

15. Moonot P, Ashwood N, Hamlet M. Early results for treatment of three and four part fractures of the proximal humerus using the PHILOS plate system. J Bone Joint Surg Br. 2007;89:1206-9. 
16. Thyagarajan DS, Haridas SJ, Jones D, Dent C, Evans R, Williams R. Functional outcome following proximal humeral interlocking system plating for displaced proximal humeral fractures. Int J Shoulder Surg. 2009;3:57-62.

17. Aggarwal S, Bali K, Dhillon MS, Kumar V, Mootha AK. Displaced proximal humeral fractures: An Indian experience with locking plates. J Orthop Surg Res. 2010;5:60.

18. Egol KA, Ong CC, Walsh M, Jazrawi LM, Tejwani NC, Zuckerman JD. Early complication of proximal humerus fractures treated with locked plates. J Ortho Trauma. 2008;22:159-64.

19. Gerber C, Worner CM, Vienne P. Internal fixation of complex fractures of the proximal humerus. J Bone Joint Surg (Br). 2004;86(60):848-55.

20. Booker S, Alfahad N, Scott M, Gooding B, Wallace WA. Use of scoring systems for assessing and reporting the outcome results from shoulder surgery and arthroplasty. World J Orthop. 2015;6(2):24451.

21. Rose PS, Adams CR, Torchia ME, Jacofsky DJ, Haidukewych GG, Steinmann SP. Locking plate fixation for proximal humeral fractures: initial results with a new implant. J Shoulder Elbow Surg. 2007;16(2):202-7.

22. Siwach R, Singh R, Rohilla RK, Kadian VS, Sangwan SS, Dhanda M. Internal fixation of proximal humeral fractures with locking proximal humeral plate (LPHP) in elderly patients with osteoporosis. J Orthop Traumatol. 2008;9(3):14953.

23. Kilic B, Uysal M, Cinar BM,Ozkoç G, Demirörs H, Akpinar S. Early results of treatment of proximal humerus fractures with the PHILOS locking plate. Acta Orthop Traumatol Turc. 2008;42(3):149-53.

24. Korkmaz MF, Aksu N, Gogus A, Debre M, Kara AN, Işiklar ZU. The results of internal fixation of proximal humeral fractures with the PHILOS locking plate. Acta Orthop Traumatol Turc. 2008;42(2):97-105.

Cite this article as: Jagiasi JD, Patel MR, Daliya SG, Bochare A, Vora M. Assessment of functional outcome of surgical management of proximal humerus fracture treated with PHILOS plate. Int J Res Orthop 2018;4:736-40. 